\title{
Experimental Investigation of Erosion and Performance of Turgo Impulse Turbine
}

\author{
Sourabh Khurana, Varun and Anoop Kumar
}

Abstract: The present study has been carried out to investigate the effect of silt size, concentration, jet velocity, nozzle angle and operating hour on the erosive wear as well as on the performance of the Turgo impulse turbine in actual flow conditions. Samples of silt were collected from the Beas River (India) near the Pandoh dam. It has been found experimentally that silt parameters, nozzle angle and operating hour of the Turgo turbine increases the erosive wear rate in the turbine components causing efficiency loss in the Turgo impulse turbine and final breakdown of hydro turbines.

Key words: Turgo turbine, nozzle angle, normalized wear, efficiency loss, silt size

\author{
Nomenclature \\ $\mathrm{W}_{\mathrm{d}}$ deformation wear at normal impact condition \\ $\varepsilon$ deformation factor \\ M the total mass of impacting particles \\ $\mathrm{V}$ velocity of particle \\ h head to the turbine \\ $\rho$ density of water \\ g acceleration due to gravity $\left(\mathrm{m} / \mathrm{s}^{2}\right)$ \\ $\mathrm{P} \quad$ electrical power output (kW) \\ Q discharge through turbine $\left(\mathrm{m}^{3} / \mathrm{s}\right)$ \\ $\eta_{g} \quad$ efficiency of generator \\ $\eta_{t} \quad$ efficiency of turbine (\%) \\ $\mathrm{C} \quad$ silt concentration (ppm) \\ S silt particle size $(\mu \mathrm{m})$ \\ $\mathrm{T} \quad$ operating time (h) \\ W normalized wear (gram) \\ Greek Symbols \\ a angle of attack \\ $\theta \quad$ impact angle $\left(^{\circ}\right)$
}

\section{Introduction}

The Turgo turbine is a medium head impulse 1 turbine $(15-300 m)$ that operates in the head range where Pelton and Francis turbines overlap (Koukouvinis, Anagnostopoulos et al 2011). These turbines achieve operational efficiency of more than $84 \%$. Turgo turbines have a flat efficiency curve and provide excellent part load efficiency; so they can be used for large flow rate variations. In Turgo turbines, jet strikes the runner plane at an angle of $25^{\circ}$ (Anagnostopoulos and Papantonis 2007).

Silt erosion in hydraulic turbines is a major problem in most of the hydro-electric projects around the world. In India, silt erosion problem occurs mainly in those projects which are situated in the Himalayan and in the north-eastern region (Thapa, Thapa and Dahlhaug 2012). Nepal is also facing silting problem in hydropower plants with sediment yield of about 4,240 tonnes $/ \mathrm{km}^{2}$ / year. The hydraulic turbine components which are mainly affected by silt are runner blades, nozzle, guide vanes, top and bottom ring liners, labyrinths, inlet valve seals etc (Thapa, Thapa and Dahlhaug 2012; Goyal, Singh et al 2012).
Silt erosion is the gradual removal of material caused by repeated deformation and cutting actions. It depends upon different parameters such as silt size, concentration, hardness, average velocity of particle, shape of particles, angle of impingement and material properties (Padhy and Saini 2008). Erosion of hydro turbine components is a major problem for the efficient operation of hydropower plants. This problem is more intensified if silt contains higher percentage of quartz, which is extremely hard (hardness 7 in Moh's scale) (Tong 1981; Singh 1990).

There are two modes of erosive wear, called the ductile mode of erosive wear and the brittle mode of erosive wear. The maximum erosion rate for ductile materials has been observed between $10^{\circ}$ to $30^{\circ}$, whereas lower erosion is found to occur around normal impact. For brittle materials, the erosion rate increases as the angle of impingement increases and is highest at normal impingement (Neupane 2010).

The aim of the present study is to analyze the effect of the nozzle angle and silt parameters on the performance as well as on the erosion of the Turgo impulse turbine.

\section{Literature Review}

Koukouvinis, Anagnostopoulos et al (2011) used the SPH method to access the performance of two different Turgo turbine runners and compared it with Computational Fluid Dynamics (CFD) solver Fluent. They found that the SPH method produces similar results in much less time than the fluent software.

Williamson, Stark et al (2012) have developed a two dimensional quasi steady state model for a Turgo turbine and then compared it with test results. They found that the performance of the turbine had been improved by $5 \%$ at $3.5 \mathrm{~m}$ head and at $1.0 \mathrm{~m}$ head, while $20 \%$ improvement in efficiency took place for $20 \mathrm{~mm}$ nozzle diameter at a jet inclination of 100 with the jet $6 \mathrm{~mm}$ from the top of cup.

Wellinger and Metallk (1949) determined the erosion for ductile (carbon steel) and brittle material (high carbon steel) as a function of impact angle. The hard and brittle steel appeared to be more erosion resistant at low impact angles than the soft steel, while at high impact angles soft 
and ductile steel appeared to be more erosion resistant.

Pool, Dharan and Finnie (1986) conducted an experimental study of polymer composite materials on an erosion wear tester. The authors concluded that maximum erosion for a ductile material occurred at about $20^{\circ}$, and for brittle materials maximum erosion occurred at $90^{\circ}$.

Lin, $\mathrm{Wu}$ and Yeh (2001) conducted an experiment on impingement erosion testing equipment to determine the slurry erosion characteristics of three Ti-Ni shape memory alloys and SUS304 stainless steel by using the liquid/solid impingement. The authors have concluded that more resistant $\mathrm{Ti}-\mathrm{Ni}$ alloys and less resistant SUS304 stainless steel exhibit ductile behavior, and maximum erosion was observed at $30^{\circ}$, and value of n in the relation $\varepsilon=K V^{n}$ varied between 2 and 3 for impingement angles between $15^{\circ}$ and $90^{\circ}$.

Neilson and Gilchrist (1968) simplified the equation proposed by Bitter, and found that the total wear at normal impact angle can be assumed to be contributed by deformation wear only. For deformation wear, the author has found the following equation:

$$
W_{C}=\frac{1 M(V \cos \alpha-K)^{2}}{2}
$$

\section{Range of Parameters}

The effect of the three parameters such as silt size, silt concentration and jet velocity were investigated under the present study. Sample of silt was collected from the Beas river (India) near the Pandoh Dam in which silt concentration during the monsoon season found to be

\begin{tabular}{|c|c|c|}
\hline S. No. & Parameters & Range \\
\hline $\mathbf{1 .}$ & Silt size & $370 \mu \mathrm{m}$ \\
\hline $\mathbf{2 .}$ & Silt concentration & $12000 \mathrm{ppm}$ \\
\hline $\mathbf{3 .}$ & Jet Velocity & $28.81 \mathrm{~m} / \mathrm{s}$ \\
\hline $\mathbf{4 .}$ & Operating Time & $2 \mathrm{~h}$ \\
\hline $\mathbf{5 .}$ & Nozzle angle & $20^{\circ}, 25^{\circ}, 30^{\circ}$ \\
\hline
\end{tabular}

Table 1. Range of Parameters Investigated. around 34,400 ppm (Awasthi 2001). The range of par a meters used for the present study is given in

Table 2. The silt was dried under the sun and then a sieve was used to measure the silt size.

\section{Experimental Setup and Procedure}

Figure 1 shows the experimental set up of the Turgo impulse turbine of $1.2 \mathrm{~kW}$ capacity which was fabricated and used in the present study. The main characteristics of the turbine are given in Table 2. The blades of the Turgo impulse turbine were made of brass in order to to

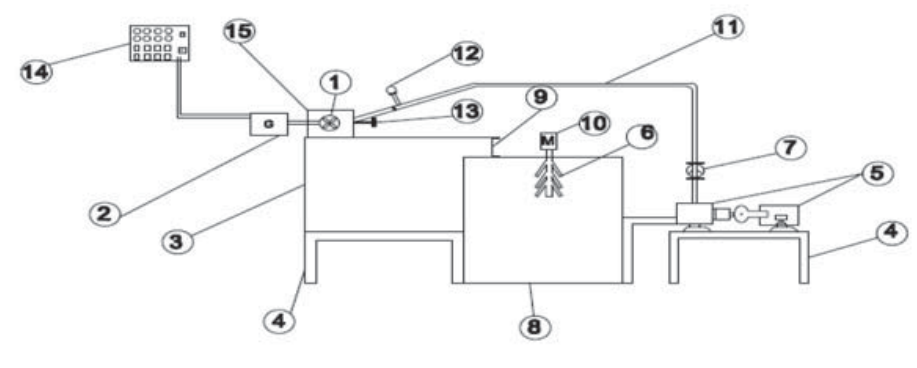

Figure 1. A Schematic Design of Experimental Setup. get a considerable amount of erosion in a short period of time. The weight of each blade was $202 \mathrm{~g}$. A $5 \mathrm{~mm}$ thick transparent acrylic casing provided to allow water behaviour to be observed easily over the turbines. Two tanks $(680 \mathrm{~mm} \times 530 \mathrm{~mm} \times 810 \mathrm{~mm})$ were fabricated for experimentation work. The first tank was used to store water and to prepare a silt water mixture of concentration $12000 \mathrm{ppm}$, and the other tank was used to measure the discharge using a rectangular notch. The silt size was measured with the help of sieve of $370 \mu \mathrm{m}$. A stirrer was attached to operate continuously during the experiment so as to supply a uniform mixture of silt and water to the turbine. In order to prepare silt water mixture of various concentrations, the required quantity of silt was added to a known volume of water in the tank. The head and flow into the turbine during the experiments were kept constant. A penstock pipe having $71 \mathrm{~mm}$ outer diameter and $3 \mathrm{~mm}$ thickness was used for supplying water to the turbine. Water was supplied by a 7.5 HP monoblock centrifugal pump having $45 \mathrm{~m}$ rated head and discharge capacity of 5.5 1/s. A spear valve was used at the end of the penstock pipe with a nozzle having a diameter of $12.5 \mathrm{~mm}$ to regulate the discharge. Water from the turbine outlet was flown through the discharge tank and then discharged to the storage tank. A control valve was used at the delivery side to maintain the required head of water at every time. The head of water was measured by a digital pressure transducer mounted on the penstock pipe at the inlet of turbine.

A generator was directly coupled with the turbine runner shaft to generate electricity. The output of the turbine was determined by considering the efficiency of the generator. A resistive load was connected to the generator through a control panel. The control panel consisted of a wattmeter, a voltmeter and load in the form of electric bulbs of different ratings. The electric load was measured to determine the output. The weight loss of the blades was measured by using an electronic weight balance having a least count of o.1 mg. The experimental study was carried out in two steps; at the start a Monoblock was used to draw \begin{tabular}{cc|c} 
clean water for different & Part & Part Name \\
heads from the storage
\end{tabular} \begin{tabular}{ll|l|l|} 
tank and supplied to the & 1. & Turgo Runner \\
\cline { 2 - 3 }
\end{tabular} turbine to estimate the $2 . \quad$ Generator Set efficiency of the turbine. $3 . \quad$ Concrete Tank As a second step, the $4 . \quad$ Stand

\begin{tabular}{|c|l|}
\hline 5. & Mono Block \\
\hline 6. & Stirrer \\
\hline 7. & Control Valve \\
\hline 8. & Steel Tank \\
\hline 9. & Rectangular Notch \\
\hline 10. & Motor \\
\hline 11. & Penstock Pipe \\
\hline 12. & $\begin{array}{l}\text { Pressure } \\
\text { Transducer }\end{array}$ \\
\hline 13. & Spear Valve \\
\hline 14. & Control Valve \\
\hline 15. & Casing \\
\hline
\end{tabular}


effect of silt parameters on the erosive wear and performance was investigated. The experiments were conducted for fixed values of silt size and concentration values of $370 \mu \mathrm{m}$ and 12,000 ppm respectively.

The nozzle angles used for the experimental work were $20^{\circ}, 25^{\circ}$ and $30^{\circ}$. Blades were dismantled from the runner after every 2 hours, and cleaned with soft cloth. Then the weight loss of each blade was measured after 2 hours. At the same time, the efficiency of the turbine was also measured. The efficiency of the turbine was also measured for clean water, and by using this value the efficiency losses were estimated.

\begin{tabular}{|c|c|c|}
\hline S. No. & Parameter & Values \\
\hline 1. & Runner Pitch diameter & $216 \mathrm{~mm}$ \\
\hline 2. & Rotation speed & $1108 \mathrm{rpm}$ \\
\hline 3. & Flow rate & $2.96 \times 10^{-3} \mathrm{~m}^{3} / \mathrm{s}$ \\
\hline 4. & Nozzle Diameter & $12.5 \mathrm{~mm}$ \\
\hline 5. & Buckets & 19 \\
\hline 6. & Mechanic Power & $1.2 \mathrm{~kW}$ \\
\hline 7. & Blade Material & Brass \\
\hline
\end{tabular}

Table 2. Main Characteristics of the Turgo Impulse Turbine.

\section{Turbine Efficiency}

To calculate the efficiency of the Turgo impulse turbine, input in terms of head and discharge was calculated. The power output was measured with the help of a wattmeter. A control panel was connected to the generator to record the power generation from the generator. It consisted of a voltmeter, a wattmeter having a least count of $1 \mathrm{~W}$, and electric bulbs were used as load. The discharge was calculated with the help of a rectangular notch. A pointer gauge was used to measure the height of water over the notch. During the experiments, input to the turbine was maintained constant by keeping the head and flow to the turbine constant. Turbine input was calculated from Equation 1.

$$
P_{i}=\rho g Q H
$$

The efficiency of the turbine was calculated from Equation 2.

$$
\eta_{t}=\frac{P_{0}}{P_{i} \times \eta_{g}} \times 100
$$

\section{Results and Discussions}

It can be observed from Figure 3 below, that maximum erosion occurs at $20^{\circ}$ nozzle angle. This feature is typical for a ductile material. In this case, material is removed by micro cutting as a result of oblique shear force, which increases the erosion rate. The amount of erosion is less at $25^{\circ}$ nozzle angle due to increase in the angle of oblique shear force due to which the cutting action gradually converts into impact erosion. Any further increase in the angle will cause pure impact erosion to take place, and the erosion rate increases considerably at an angle of $30^{\circ}$.

Figure 4 shows the effect of nozzle angle on the percentage efficiency loss of the blades for a fixed value of silt size, silt concentration, jet velocity and operating time.

From Figure 4, it can be noticed that at nozzle angle of $20^{\circ}$, the percentage efficiency loss was found to be about $2 \%$, which is higher than at angles of $25^{\circ}$ and $30^{\circ}$. This is due to the fact that at $20^{\circ}$, normalized wear is more which increases the friction on the blade surface and, hence, results in loss in efficiency. The rate of percentage efficiency loss was found to be significant in this case. This shows that the rate of percentage efficiency loss is significant for smaller nozzle angles. However, the rate of percentage efficiency loss was found to be about $1.7 \%$ for a nozzle angle of $25^{\circ}$ and $1.89 \%$ for a nozzle angle of $30^{\circ}$, due to increase in the wear rate at these angles.

\section{Conclusion}

On the basis of experimental investigation, it has been found that silt size, silt concentration, jet velocity, and

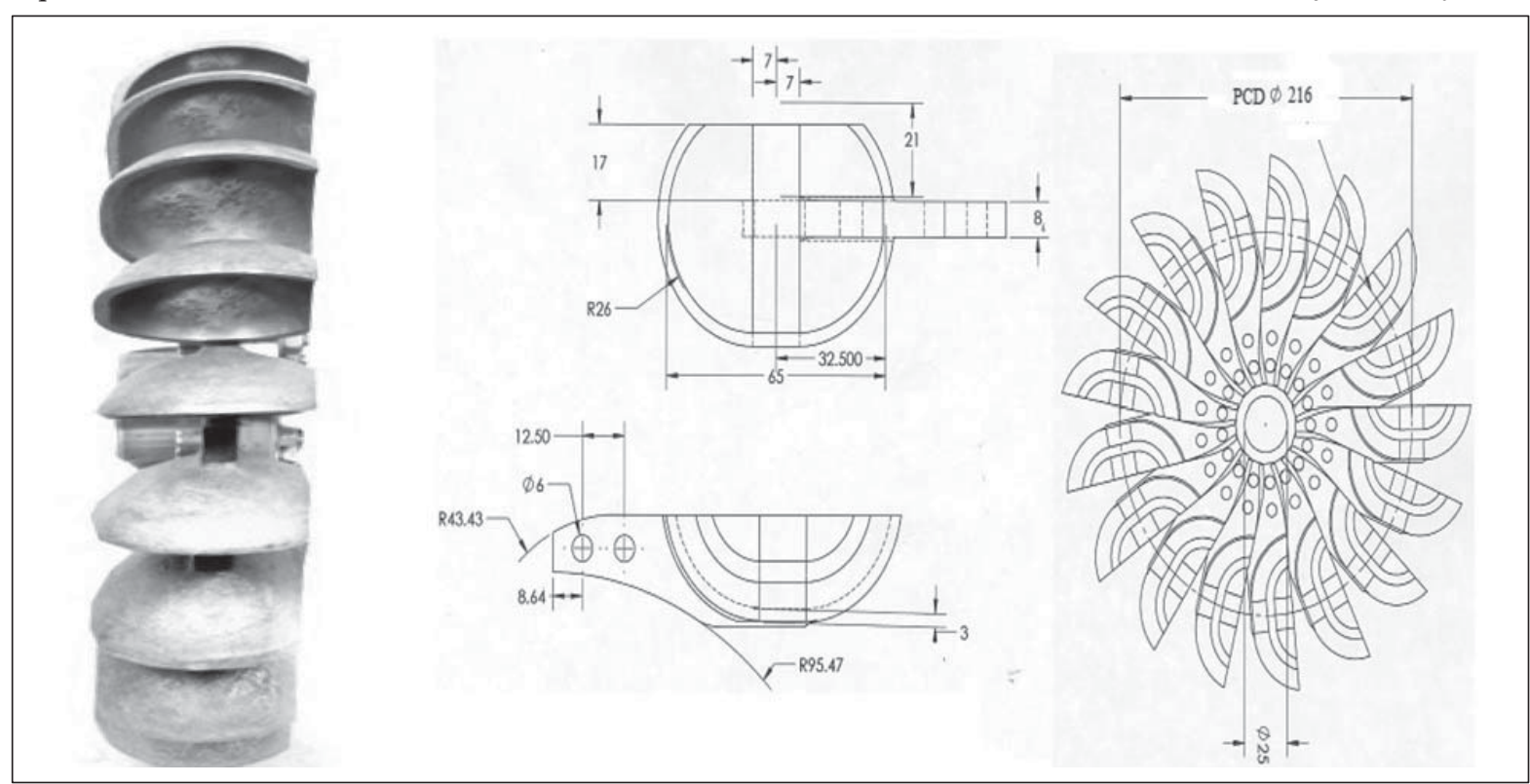

Figure 2. Runner of the Turgo Impulse Turbine. 


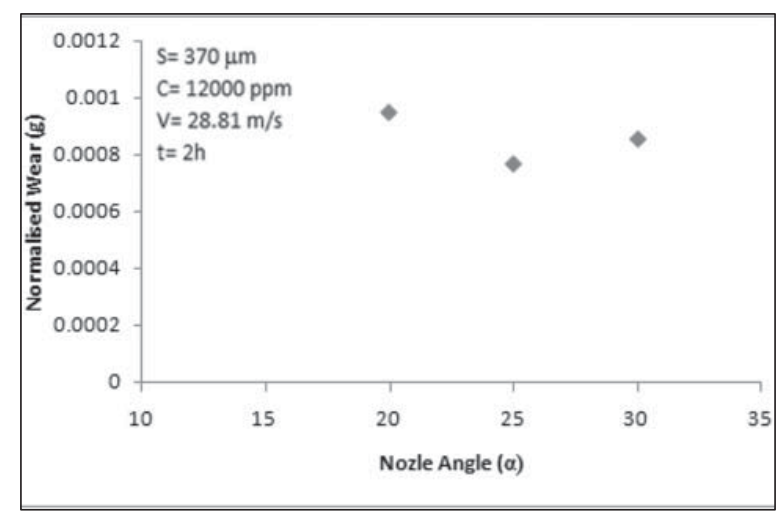

Figure 3. Effect of Nozzle Angle on Normalized Wear for Silt Size $370 \mu \mathrm{m}$, Concentration $12000 \mathrm{ppm}$, Jet Velocity $28.81 \mathrm{~m} / \mathrm{s}$, and Operating Time $2 \mathrm{~h}$.

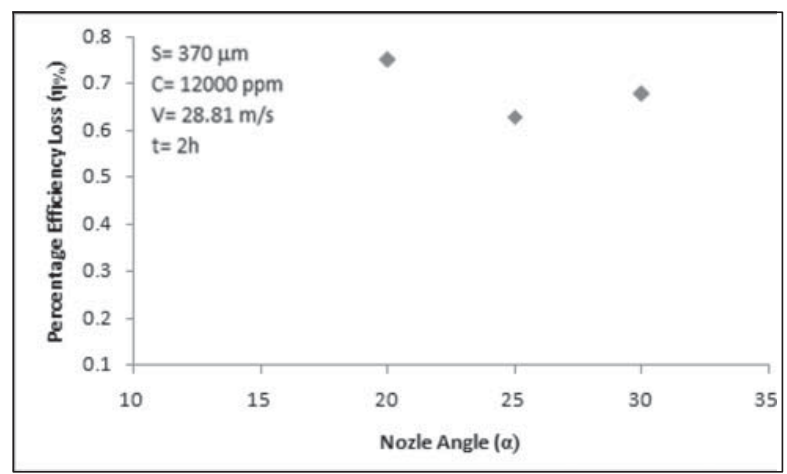

Figure 4. Effect of Nozzle Angle on Percentage Efficiency Loss for $2 \mathrm{~h}$, Silt Size $370 \mu \mathrm{m}$, Concentration 12000 ppm, Jet Velocity $28.81 \mathrm{~m} / \mathrm{s}$.

operating time affects the rate of erosion as well as performance of the Turgo impulse turbine. It can also be concluded from the experiment that maximum erosion occurs at a nozzle angle of $20^{\circ}$, and at angle of $25^{\circ}$ less erosion takes place, which is the typical behaviour for ductile materials. However, the rate of percentage efficiency loss was found to be about $2 \%$ for a nozzle angle of $20^{\circ}$ as compared to $25^{\circ}$.

Sourabh Khurana graduated in Mechanical Engineering in 2005, and later completed $M$. Tech in 2008 from the National Institute of Technology (NIT), Hamirpur (India) in Thermal Engineering with specialization in Computational Fluid Dynamics and Heat Transfer. He is doing Ph.D. at NIT, Hamirpur. He is presently working as Assistant Professor at the School of Engineering and Technology, Shoolini University, Bajhol (Solan). His area of interest is Fluid Mechanics, Heat Transfer, and Hydro power.

Corresponding address: sourabhnith@gmail.com.

Varun, Ph.D., is presently working as Assistant Professor in the Department of Mechanical Engineering at NIT, Hamirpur, India. His area of interest is Solar Air Heater, Life cycle Assessment and Heat Transfer. He has published more than 60 papers in International/ National Journals.

Corresponding address: varun7go@gmail.com.
Anoop Kumar, Ph.D., is presently working as Professor in the Department of Mechanical Engineering at NIT, Hamirpur, India. His area of interest is CFD, Turbo machines, Particle capturing and Heat Transfer. He has published more than 15 papers in International/ National Journals.

Corresponding address: jas.anoop@gmail.com.

\section{References}

Anagnostopoulos, J. and D. Papantonis, 2007, "Flow modeling and runner design optimization in Turgo water turbines", World Academy of Science, Engineering and Technology, vol. 28 pp 206-211.

Awasthi, A.K., 2001, Desanding for small hydro- An innovative approach. 2nd International conference on silting problems in hydropower plants 26-28 September Bangkok Thailand.

Goyal, D.K., Harpreet Singh, Harpreet Kumar and Varinder Sahni, 2012, "Slurry erosion behaviour of HVOF sprayed WC-10Co and $\mathrm{Al}_{2} \mathrm{O}_{3}+13 \mathrm{TiO} 2$ ", Wear vol. 289 pp 46-57.

Koukouvinis, P., J. Anagnostopoulos and D. Papantonis, 2011, "SPH method used for flow predictions at a Turgo impulse turbine: Comparison with fluent", World Academy of Science, Engineering and Technology vol. 79, pp 659-666.

Khosrowpanah, S., A. A. Fiuzat and M. L. Albertson, 1988, "Experimental study of cross flow turbine", Journal of Hydraulic Engineering, vol. 114, pp 299314.

Lin, HC., S.K. Wu and C.H. Yeh, 2001, "A comparison of slurry erosion characteristics of TiNi shape memory alloys and SUS304 stainless steel", Wear vol.249, pp $557-65$.

Neilson, J.H. and A. Gilchrist, 1968, Erosion by a stream of solid particles, Wear vol. 11 pp 111-22.

Neupane, H., 2010, "Sediment erosion of hydro turbines". Doctoral Thesis at Norwegian university of science and technology.

Padhy, M.K. and R.P. Saini, 2008, "A review of silt erosion in hydro turbines", Renewable and Sustainable Energy Reviews vol. 12 pp 1974-87.

Pool, K.V., C.K.H. Dharan and I. Finnie, 1986, "Erosive wear of composite materials", Wear vol. 107, pp 1-12.

Singh, S.C., 1990, "Operational problems and development of a new runner for silty water", International Water Power and Dam Construction.

Thapa BS., Thapa B and Dahlhaug OG., 2012, "Empirical modelling of sediment erosion in Francis turbines", Energy vol. 41, pp 386-391.

Tong, D., 1981, Cavitation and wear on hydraulic machines, International Water Power and Dam Construction.

Wellinger, R. and Z. Metallk, 1949, 40361.

Williamson, S.J., B.H. Stark and J.D. Booker, 2012, "Performance of a low head pico hydro Turgo turbine", Applied Energy vol. 102, pp 1114-1126. 